\title{
Gramíneas do cerrado: carboidratos não-estruturais e aspectos ecofisiológicos
}

\author{
Amanda de Souza ${ }^{1}$, Moemy Gomes de Moraes $^{2}$ e Rita de Cássia Leone Figueiredo Ribeiro ${ }^{1,3}$
}

Recebido em 18/02/2004. Aceito em 16/07/2004

\begin{abstract}
RESUMO-(Gramíneas do cerrado: carboidratos não-estruturais e aspectos ecofisiológicos). As gramíneas reúnem características que as destacam como grupo evoluído e diversificado de plantas. Possuem desempenho fotossintético eficiente em diversas condições, são eficientes na produção e dispersão de diásporos, possuem sistema radicular fasciculado, além de produzirem estolhos e rizomas. O conjunto destes atributos faz com que gramíneas sejam apropriadas para a recomposição de áreas degradadas, atuando como pioneiras na sucessão ecológica. Se de um modo isto possibilita vantagem na ocupação de áreas em seu habitat original, por outro podem ser atributos que incrementam o grau de invasibilidade de uma espécie em outro ambiente. A composição de carboidratos não-estruturais e a alta produção de biomassa são discutidas visando fornecer subsídios para utilização das vantagens adaptativas das gramíneas em programas de manejo de reservas naturais.
\end{abstract}

Palavras-chave: gramíneas, carboidratos não-estruturais, cerrado, invasão de reservas biológicas

ABSTRACT - (Grasses of the cerrado: non-structural carbohydrates and ecophysiological aspects). Grasses combine characteristics that distinguish them as an evolved and diversified group of plants. They present an efficient photosynthetic metabolism under several conditions, as well as a high production and spreading of diaspores. Besides their fasciculate roots, some species can present stolons and rhizomes. Together, such attributes make grasses appropriated for the recovery of degraded areas, acting as pioneers in the ecological succession. However, if these characteristics enable grasses to occupy areas in their original habitat, they also increase their ability of invading other environments. Non-structural carbohydrates composition and high biomass production are discussed aiming at providing subsidies for the use of those adaptive advantages in programs for conservation of natural reserves.

Key words: grasses, non-structural carbohydrates, cerrado, biological invasion

\section{Introdução}

Dentre os biomas brasileiros, o cerrado é o segundo maior em termos de área de ocorrência. Sua região central de distribuição é o Planalto Central, ocorrendo também em áreas isoladas e periféricas menores. A sazonalidade climática é uma de suas principais características.

Como conseqüência da sazonalidade, a vegetação do cerrado desenvolveu diversas adaptações morfológicas e fenológicas. Como exemplo do primeiro caso, observam-se sistemas subterrâneos espessados e profundos, possibilitando o alcance de regiões do solo onde há disponibilidade de água mesmo na estação seca. Quanto à fenologia, diversas espécies do cerrado entram em fase de dormência durante o período seco, após abscisão foliar e morte dos ramos (Mantovani \&
Martins 1988). Além dessas adaptações, espécies herbáceas do cerrado apresentam modificações no metabolismo de carboidratos solúveis, com armazenamento de polissacarídeos de reserva no final da fase de crescimento vegetativo e despolimerização destes nos períodos com intensa demanda energética (Carvalho \& Dietrich 1993; Carvalho \& FigueiredoRibeiro 2001).

Apesar da intensificação dos estudos sobre o cerrado, sua flora ainda não é totalmente conhecida. Mais de 6.000 espécies de angiospermas já foram identificadas e os trabalhos de levantamento florístico destacam os estratos herbáceo e subarbustivo como responsáveis pela maior riqueza de espécies (Castro et al. 1999). Leguminosae e Asteraceae são as famílias mais importantes desse bioma. Poaceae é a família com maior número de espécies no estrato herbáceo,

\footnotetext{
1 Instituto de Botânica de São Paulo, C. Postal 4005, CEP 01061-970, São Paulo, SP, Brasil

2 Universidade Federal Fluminense, C. Postal 100436, CEP 24001-970, Niterói, RJ, Brasil

3 Autor para correspondência: ritarib@usp.br
} 
que pode conter até $25 \%$ do número total de espécies em áreas de cerrado na região central do Brasil (Filgueiras et al. 1998). A partir de análise recente realizada em Área de Relevante Interesse Ecológico (ARIE) localizada no Distrito Federal, com porções de Campo Limpo, Campo Sujo, Campo de Murunduns e Campo Cerrado foram listadas 107 espécies de Poaceae, sendo 82 nativas e 25 exóticas (Rodriguesda-Silva \& Filgueiras 2003), evidenciando que a invasão biológica por gramíneas exóticas vem sendo uma ameaça à biota nativa dessas áreas.

Como uma das maiores famílias de angiospermas, as gramíneas (Poaceae) são de particular interesse ao homem, por incluir espécies importantes na alimentação humana como Triticum aestivum L. (trigo), Zea mays L. (milho), Oryza sativa L. (arroz) e Saccharum officinarum L. (cana-de-açúcar). Incluem também espécies forrageiras, como Urochloa decumbens (Stapf) Webster (braquiária) e Panicum maximum Jacq. (capim-colonião), fontes principais de alimentação para o gado. Além disso, diversos membros da família são dominantes ecológicos, cobrindo cerca de $20 \%$ da superfície terrestre (Kellogg 2001).

O sucesso ecológico das Poaceae reflete-se na ampla distribuição da família, nos mais diversos tipos de hábitats, incluindo a região da Antártida (Kellogg 1998). Tal sucesso deve-se, principalmente, à diversidade genética da família, que resultou em adaptações morfo-fisiológicas a ambientes diversificados. Dentre essas adaptações, destacam-se o surgimento da tolerância à dessecação e a capacidade de se desenvolver em ambientes abertos e secos, uma vez que as primeiras gramíneas eram plantas de bordas de florestas e áreas bastante sombreadas (Kellogg 2001).

\section{Fotossíntese em gramíneas}

Um dos aspectos que refletem a diversidade das gramíneas é a ocorrência da via fotossintética $\mathrm{C}_{4}$, ou ciclo de Hatch-Slack-Kortschak. Das 7.500 espécies de plantas superiores que apresentam esse tipo de fotossíntese, 4.500 são gramíneas. Uma síntese do conhecimento sobre a biologia de plantas $\mathrm{C}_{4}$ foi publicada recentemente por Sage (2004), sendo apresentada uma visão clara sobre a evolução do padrão $\mathrm{C}_{4}$ em plantas superiores. $\mathrm{O}$ metabolismo fotossintético $\mathrm{C}_{4}$ consiste de uma série de modificações anatômicas e bioquímicas que concentram o $\mathrm{CO}_{2}$ nos locais de ação da ribulose 1,5 bisfosfato carboxilase/ oxigenase (RUBISCO). Esta enzima é suprimida nas células do mesofilo, de forma que o $\mathrm{CO}_{2}$ liga-se primariamente ao fosfoenolpiruvato (PEP) pela ação da fosfoenolpiruvato carboxilase (PEPc), formando o ácido oxaloacético (com quatro átomos de $\mathrm{C}$ ). $\mathrm{O}$ ácido oxaloacético é então reduzido a malato, (ou aspartato, em algumas espécies) que atua como substância transportadora de $\mathrm{CO}_{2}$, sendo transferido por difusão até as células da bainha vascular. Nos cloroplastos destas células, o malato ou o aspartato são processados cataliticamente por enzimas específicas e transformados em $\mathrm{CO}_{2}$ e piruvato. Esse mecanismo resulta na concentração de $\mathrm{CO}_{2}$ no interior das células da bainha, sendo este liberado e interceptado pela RUBISCO e então reduzido na via das pentosesfosfato. Existem três subtipos da via $\mathrm{C}_{4}$ de acordo com a enzima responsável pela descarboxilação do ácido $\mathrm{C}_{4}$ nas células da bainha: NADP ${ }^{+}$-ME (nicotinamidaadenina-dinucleotídeo-fosfato, enzima málica), $\mathrm{NAD}^{+}$-ME (nicotinamida-adenina-dinucleotídeo, enzima málica), e PEP-ck, no qual a enzima é a PEP carboxiquinase (Chapman 1996).

Adicionalmente às diferenças bioquímicas, espécies $\mathrm{C}_{4}$ possuem alterações anatômicas e ultraestruturais. Estas plantas possuem dois tipos de células fotossintetizantes: aquelas da camada celular em torno do feixe vascular, a bainha, que embora estejam presentes em outras espécies, somente em plantas $\mathrm{C}_{4}$ possuem cloroplastos, e as do mesofilo. Nessas espécies, as células da bainha possuem paredes espessas, em alguns casos suberizadas, não havendo acesso direto aos espaços intercelulares do mesofilo. Estas características conferem à bainha um aspecto de "coroa", que deu origem ao termo anatomia "Kranz" (coroa, em alemão). Em contraste, o mesofilo apresenta células com paredes delgadas e abundantes espaços intercelulares. As células do mesofilo ligamse às células da bainha por um amplo número de plasmodesmatas, o que é essencial para a eficiência na transferência de $\mathrm{CO}_{2}$ para estas células (Bowyer $\&$ Leegood 1997).

Pesquisas recentes têm demonstrado que a via $\mathrm{C}_{4}$ não depende necessariamente da ocorrência de anatomia Kranz. Borszczowia aralocaspica Bunge (Chenopodiaceae), que não apresenta esta peculiaridade anatômica, possui fotossíntese $\mathrm{C}_{4}$ (Voznesenskaya et al. 2001), possibilitada pela compartimentação das enzimas em dois tipos diferentes de cloroplastos, que ocupam sítios distintos na célula do mesofilo. Adicionalmente, Hibberd \& Quick (2002) verificaram nas células das bainhas vasculares do pecíolo e do caule de tabaco, uma espécie típica $\mathrm{C}_{3}$, 
atividade elevada das enzimas do metabolismo $\mathrm{C}_{4}$, com suprimento de $\mathrm{CO}_{2}$ do tecido vascular, ao invés dos estômatos.

Entre as subfamílias de Poaceae, a distribuição da via fotossintética varia: Pooideae e Bambusoideae são exclusivamente do tipo $\mathrm{C}_{3}$; Arundinoideae é predominantemente $\mathrm{C}_{3}$ (embora o gênero Aristida seja $\mathrm{C}_{4}$ ) e Chloridoideae e Panicoideae são predominantemente $\mathrm{C}_{4}$. Dentre as Panicoideae, as espécies $\mathrm{C}_{3}$ encontradas são associadas a ambientes úmidos e alagados (Medina et al. 1999). Em levantamento sobre o tipo fotossintético de gramíneas baseado na ocorrência de anatomia Kranz, Klink \& Joly (1989) encontraram Echinolaena inflexa (Poir.) Chase, uma gramínea nativa abundante no cerrado e pertencente à subfamília Panicoideae, e classificaram-na como $\mathrm{C}_{3}$, fato confirmado posteriormente por Medina et al. (1999) através de análise do carbono-13 $\left(\delta^{13}\right)$.

Devido à maior eficiência no uso de água e de nutrientes, as plantas $\mathrm{C}_{4}$ são capazes de crescer em ambientes que são muito severos para espécies $\mathrm{C}_{3}$, como zonas hipersalinas, rochas e em solos áridos. $\mathrm{O}$ mecanismo de concentração do $\mathrm{CO}_{2}$ resulta em vantagens para as espécies que possuem a via $\mathrm{C}_{4}$ com relação à produção de matéria seca em condições de alta temperatura e estresse hídrico moderado. A fotossíntese nessas plantas atua de maneira eficiente mesmo com concentrações baixas de $\mathrm{CO}_{2}$ no interior da folha, portanto reduzindo o tempo e grau de abertura dos estômatos. Adicionalmente, não há fotorrespiração no mesofilo. A alta eficiência na carboxilação também é vantajosa para as plantas $\mathrm{C}_{4}$ em locais com alta intensidade de radiação. Por apresentarem baixo teor protéico nos cloroplastos do mesofilo, as plantas $\mathrm{C}_{4}$ também necessitam de quantidades menores de nitrogênio. Por outro lado, espécies $C_{3}$ são melhor adaptadas a ambientes sombreados, úmidos e com temperaturas mais baixas (Larcher 2000).

É na eficiência fotossintética que se baseia o interesse econômico no cultivo das Poaceae; por um lado, através da produção primária de fitomassa para a alimentação de herbívoros, no caso das espécies forrageiras, e por outro, através de fontes amiláceas, como no caso dos cereais, que constituem a base da alimentação de muitos povos. Um outro aspecto que merece destaque é a presença de bactérias fixadoras de nitrogênio na rizosfera de gramíneas tropicais e de outras culturas alimentíceas mundiais (milho, arroz), além de espécies forrageiras. Tratam-se de bactérias dos gêneros Azospirillum, Acetobacter e Herbaspirillum, os dois últimos tamém encontrados em caules e folhas de cana-de-açúcar (Becking 1981, Raven et al. 1999), envolvendo a participação de glicose e de polissacarídeos de superfície. Estudos recentes têm enfatizado a importância dessa interação na biossíntese de reguladores de crescimento em plantas (Steenhoudt \& Vanderleyden 2000).

\section{Carboidratos não-estruturais em gramíneas}

O ciclo de redução do carbono resulta na produção de carboidratos, que possuem diversas atribuições nos vegetais, como o armazenamento e translocação de carbono e a proteção contra vários tipos de condições ambientais adversas, como a restrição hídrica, alta salinidade e temperaturas extremas (Keller \& Pharr 1996).

Os vegetais apresentam diferentes tipos de carboidratos de reserva, solúveis e insolúveis. A estrutura química e a concentração desses compostos variam entre espécies, órgãos, tecidos e células, bem como ao longo do dia, e nas diferentes estações anuais (Lewis 1984). A Figura 1 mostra a estrutura de alguns dos principais carboidratos não-estruturais encontrados em gramíneas.

Os monossacarídeos glicose e frutose ocorrem em todas as plantas vasculares, como produtos de hidrólise de seus ésteres fosfato, quanto do dissacarídeo sacarose. Podem também derivar da hidrólise de seus polímeros amido e frutano. Ambos são substratos da enzima hexoquinase, através da qual são metabolizados como fonte de energia pela glicólise, pela via das pentoses-fosfato e do ciclo do ácido cítrico. Constituem também os principais esqueletos de carbono para a síntese de intermediários dessas vias, e ainda são unidades para a síntese de oligo e polissacarídeos.

A sacarose, por sua vez, é o principal açúcar de plantas vasculares. É encontrada universalmente em vegetais, geralmente em altas concentrações. Devido à sua natureza não redutora, esse açúcar pode ser translocado e armazenado nos vacúolos celulares, não sendo metabolizado até ser necessário. É uma molécula altamente solúvel e quimicamente inerte quando em contato com proteínas, pois não forma ligações covalentes com grupos amino livres. É também a molécula que retém a maior energia livre de hidrólise conhecida para uma ligação glicosídica. A primeira enzima envolvida em sua síntese é a sacarose fosfato sintase (SPS), que catalisa a síntese de sacarose 6-fosfato através de uma transglicosilação de UDP-glicose a frutose-6-fosfato. Uma segunda enzima, a sacarose fosfatase (SPP), hidrolisa a sacarose 

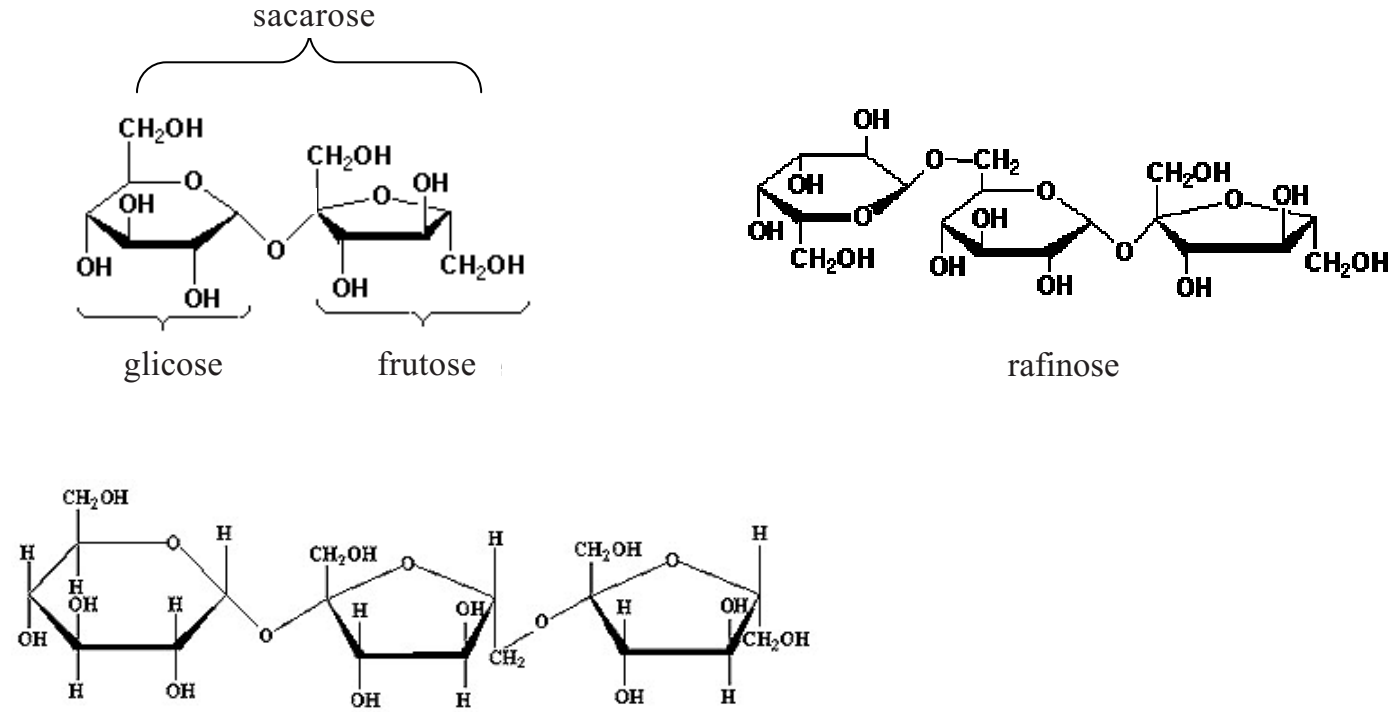

6-cestose
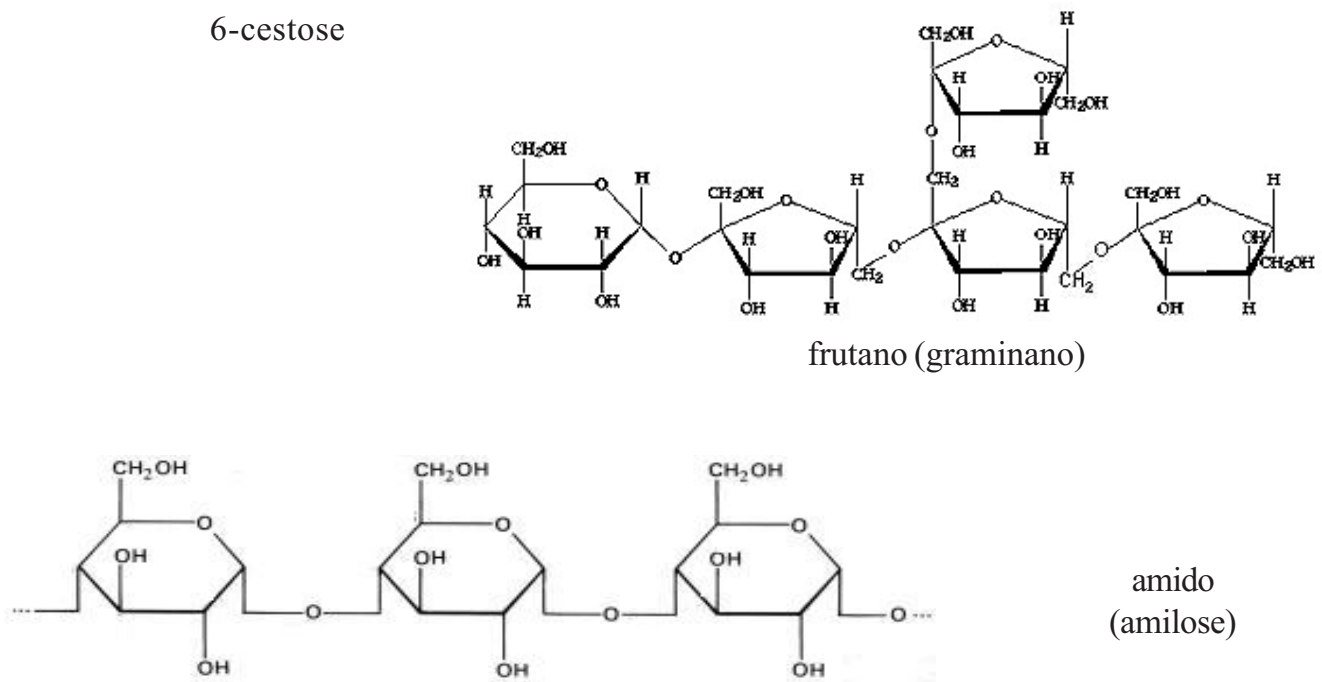

amido

(amilose)
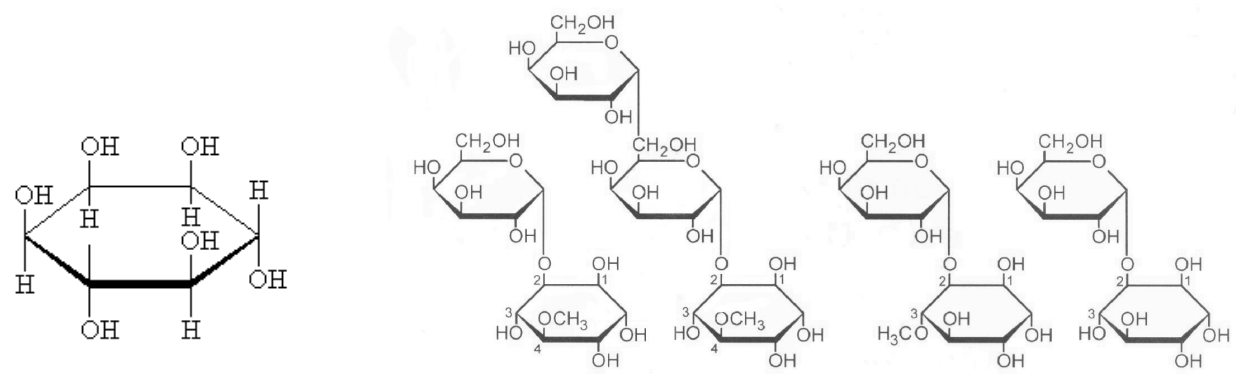

myo-inositol

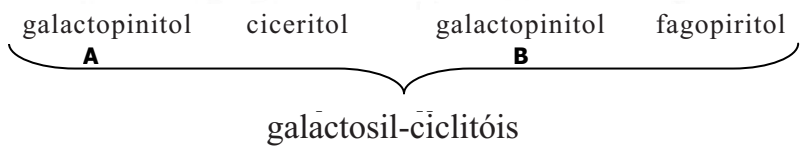

Figura 1. Estrutura química de alguns dos principais carboidratos não-estruturais e ciclitóis encontrados em plantas superiores. 
6-fosfato liberando sacarose livre e $\mathrm{P}_{\mathrm{i}}$. Uma outra via biossintética envolve a enzima sacarose sintase (SS), que catalisa reversivelmente a síntese de sacarose a partir de UDP-glicose e frutose. No entanto, esta enzima tende a atuar mais significativamente no sentido de hidrólise do dissacarídeo (Avigad \& Dey 1997).

Além de fornecer substrato para síntese de material celular e de outros carboidratos de reserva, como amido e frutano, a sacarose atua como molécula sinalizadora do metabolismo e do desenvolvimento vegetal, através da modulação da expressão gênica e do turnover de proteínas (Farrar et al. 2000).

O segundo principal carboidrato em plantas é o amido, com função de reserva. Seu sítio de deposição, no entanto, difere do da sacarose, sendo em cloroplastos nas folhas e em amiloplastos nos tecidos não-fotossintetizantes. Existe uma relação dinâmica ativa do fluxo de açúcares entre o amido e a sacarose, mas a transferência destes não é direta e envolve diversos passos enzimáticos (Avigad \& Dey 1997).

O acúmulo de amido geralmente dá-se em grânulos que variam em forma e tamanho entre as diferentes espécies de plantas. Nos cloroplastos, de um modo geral, o amido é acumulado nos períodos de luz, sendo rapidamente degradado no período de escuro e seus produtos exportados para o citosol, onde são principalmente convertidos a sacarose. Nos amiloplastos de tecidos não-fotossintetizantes, como sementes, raízes e tubérculos, o amido é acumulado por períodos mais prolongados e mobilizado quando o crescimento é retomado (Ong et al. 1994).

O amido é constituído por duas frações polissacarídicas distintas: a amilopectina, que é a fração majoritária $(65-85 \%)$ e uma das maiores moléculas conhecidas, podendo atingir massa molecular da ordem de $10^{7}-10^{8} \mathrm{Da}$. É formado por unidades de glicose unidas por ligações $\alpha(1 \rightarrow 4)$ e ramificada de forma complexa, através de ligações $\alpha(1 \rightarrow 6)$, responsáveis pelo empacotamento semi-cristalino denso desses glucanos. A amilose é a fração minoritária dos grãos de amido (15-35\%), não possui estrutura semi-cristalina e consiste de moléculas menores $\left(10^{4}-10^{5} \mathrm{Da}\right)$, com baixos níveis de ramificação (menos de $1 \%$ ) através de ligações $\alpha(1 \rightarrow 6)$ entre as unidades de glicose (Ball et al. 1998).

Informações recentes mostraram que o amido foliar de Arabidopsis thaliana (L.) Heynh. contém os mesmos polímeros, em concentrações similares e com mesmo nível de organização molecular estrutural do amido de reserva de sementes, tubérculos e folhas de outras plantas superiores. Apresenta-se com orientação radial, em camadas semi-cristalinas e amorfas intercaladas, na forma de anéis de crescimento. A amilopectina, em particular, tem estrutura cristalina, que se repete com periodicidade de $9 \mathrm{~nm}$. Como os fatores que determinam o tamanho dos grãos de amido, sua forma e seu número em diferentes espécies não são conhecidos, o uso de mutantes com alterações na morfologia e no número desses grãos poderá representar uma ferramenta útil para responder a essas questões (Zeeman et al. 2002).

Embora sejam os carboidratos mais abundantes, muitas espécies não utilizam o amido e a sacarose como fonte primária de carbono, mas sim sacarosiloligossacarídeos altamente solúveis, como os frutanos, oligossacarídeos da família da rafinose, ou, ainda, os polióis como manitol e sorbitol (Büchi et al. 1998).

Os frutanos constituem o terceiro grupo de carboidratos não-estruturais de maior ocorrência entre os vegetais (Carvalho \& Figueiredo-Ribeiro 2001). Estes compostos são polímeros de frutose derivados da sacarose e consistem de séries homólogas de oligo e polissacarídeos não-redutores. O elemento mais simples da série é um trissacarídeo denominado monofrutosil-sacarose, para o qual três isômeros foram caracterizados: 1-cestose, 6-cestose e neo-cestose. Em Asteraceae, predominam os frutanos do tipo inulina, que são baseados na série da 1-cestose, nos quais as unidades de frutose estão unidas por ligações $\beta(2 \rightarrow 1)$. Em gramíneas, por outro lado, predominam os frutanos do tipo fleano, baseados na série da 6-cestose (Fig. 1), nos quais as unidades de frutose estão unidas por ligações $\beta(2 \rightarrow 6)$. Segundo Edelman \& Jefford (1968), em Helianthus tuberosus L. (Asteraceae) a síntese de frutanos inicia-se com a transglicosilação entre duas moléculas de sacarose, catalisada pela enzima sacarose:sacarose frutosil transferase (SST), que origina o trissacarídeo 1-cestose. O alongamento da cadeia é catalisado pela enzima frutano:frutano frutosil transferase (FFT). Este modelo, entretando, não explica o metabolismo de frutanos em gramíneas, em que uma outra enzima, a sacarose:frutano 6-frutosil transferase (6-FFT), inicia ou alonga as cadeias de oligofrutanos com ligação $\beta(2 \rightarrow 6)$ (Duchateau et al. 1995).

Uma outra série de sacarosil-oligossacarídeos é a dos oligossacarídeos da família da rafinose (RFOs). A rafinose é um trissacarídeo de ampla ocorrência em vegetais superiores, sendo encontrado principalmente em folhas, caules e órgãos de reserva, como sementes, raízes e rizomas (Avigad \& Dey 1997). Seu nível em folhas é baixo, no entanto é translocado e acumulado em altas concentrações nos tecidos de reserva. 
A biossíntese dos RFOs baseia-se na ação sequencial de $\alpha$-D-galactosiltransferases (Kandler \& Hopf 1984). Em um primeiro momento, ocorre a transferência de uma galactosila para uma molécula de myo-inositol, formando o galactinol. Subseqüentemente, o galactinol doa a unidade de galactose para uma molécula de sacarose, formando a rafinose, com a liberação de uma molécula de myo-inositol. Os membros superiores desta série (estaquiose, verbascose e ajugose, respectivamente) são seqüencialmente formados pela ação de galactosiltransferases específicas, a partir da doação da unidade de galactose pelo galactinol.

Além dessa via biossintética bem estabelecida, Bachmann et al. (1994) observaram a existência de uma enzima galactinol-independente, que catalisa o alongamento da cadeia através da transferência de galactosila entre duas moléculas de RFO. Mais recentemente, Richter et al. (2000) e Peterbauer \& Richter (2001) demostraram que um grupo de galactosil-ciclitóis, tais como galactosil-ononitol e galactopinitol A, podem substituir o galactinol como doador de galactosila na biossíntese de estaquiose. Estes galactosil-ciclitóis representam derivados metilados do galactinol, no entanto, evidências bioquímicas sugerem que eles sejam sintetizados através da galactosilação galactinol-dependente dos ciclitóis ononitol e pinitol, respectivamente (Peterbauer et al. 1998; Hoch et al. 1999).

Em muitas espécies, a série da rafinose está envolvida no processo de germinação. Além disso, estes galactosil-oligossacarídeos são importantes compostos de proteção contra dessecação e outros agentes ambientais de estresse, promovendo a formação de um estado vítreo que protege macromoléculas (Leopold et al. 1994) ou estabilizando membranas diretamente, através da substituição de moléculas de água entre as extremidades polares dos fosfolipídeos (Crowe et al. 1996).

Bender e Smith (1973) separaram as espécies de gramíneas em dois grupos, de acordo com o tipo de polissacarídeo não-estrutural primário acumulado nos entrenós basais: as gramíneas de origem tropical e subtropical, que acumulam amido na base do caule, e as de origem temperada, que acumulam frutanos.

Acredita-se que nas gramíneas de regiões temperadas que acumulam grandes quantidades de frutanos em suas folhas durante o outono e inverno, esses compostos tenham papel crioprotetor (Pollock \& Cairns 1991), sendo a síntese dos mesmos relacionada a altas concentrações de sacarose (Pollock
1984; Koroleva et al. 1998). Em espécies de regiões tropicais, no entanto, o aumento nas concentrações de sacarose estimula o acúmulo transitório de amido em cloroplastos ou reduz a taxa de fixação de carbono (Pollock et al. 1995).

Algumas espécies de gramíneas armazenam carboidratos não-estruturais nos tecidos fotossintéticos se a produção de fotoassimilados é maior que sua utilização nos processos de crescimento (Pollock 1986). Chatterton et al. (1972) observaram acúmulo de amido nos cloroplastos foliares de espécies tropicais submetidas a temperaturas baixas, enquanto em espécies $\mathrm{C}_{3}$ de regiões temperadas, condições de baixa temperatura estimularam o acúmulo de frutanos nos vacúolos (Chatterton et al. 1991).

Uma triagem realizada por Chatterton et al. (1989) comparou os carboidratos não-estruturais de várias espécies de gramíneas dos tipos $\mathrm{C}_{3}$ de regiões temperadas, $\mathrm{C}_{3}$ de origem Gondwânica (espécies que evoluíram no antigo continente Gondwana, o qual se separou em Austrália, Antártica, África, América do Sul, Madagascar e Índia), e $\mathrm{C}_{4}$ de regiões tropicais, cultivadas sob dois regimes térmicos. Através desse estudo foi possível constatar que temperaturas baixas levavam a um aumento pronunciado no acúmulo de carboidratos não-estruturais totais, como amido, sacarose e frutanos. A presença desse último grupo de carboidratos, no entanto, foi observada somente nas espécies $\mathrm{C}_{3}$ de origem temperada, nas quais o amido também foi encontrado, demonstrando que frutanos e amido não são necessariamente formas alternativas de carboidrato de reserva em gramíneas. Estudos realizados com gramíneas do cerrado da Reserva Biológica e Estação Experimental de MojiGuaçu (SP) não mostraram a presença de frutanos nessas plantas, destacando-se entre os principais carboidratos glicose, frutose, sacarose, amido, traços de rafinose e malto-oligossacarídeos e também polióis (Moraes et al. 2002).

\section{Invasão biológica do cerrado por gramíneas exóticas}

As gramíneas reúnem características que as destacam como um grupo evoluído e diversificado de plantas. Possuem desempenho fotossintético eficiente em diversas condições, são eficientes na produção e dispersão de diásporos, possuem sistema radicular fasciculado, além de produzirem estolhos e rizomas. O conjunto destes atributos faz com que gramíneas sejam apropriadas para a recomposição de áreas 
degradadas, atuando como pioneiras na sucessão ecológica (Chapman 1996). Se de um modo isto possibilita vantagem na ocupação de áreas em seu habitat original, por outro pode incrementar o grau de invasibilidade de uma espécie em outro ambiente.

A invasão biológica é o segundo fenômeno causado pelo homem que mais provocou extinção de espécies até a atualidade, superando as alterações climáticas e as mudanças na composição da atmosfera. Apenas a ocupação de terras causou maior número de espécies extintas. Em áreas invadidas, podem ocorrer alterações nos processos do ecossistema, resultando em mudanças de caráter composicional e funcional (D'Antonio \& Vitousek 1992). Vitousek (1990) sugere três situações em que ecossistemas podem ser alterados por invasões: através de mudanças nos níveis de suprimento de recursos, na estrutura trófica e na freqüência e intensidade de fogo. Essas alterações representam uma ameaça a populações e comunidades nativas e, quando ocorrem em áreas amplas, podem resultar em mudanças globais.

D'Antonio e Vitousek (1992) destacaram as gramíneas como um grupo extremamente eficiente na capacidade de perturbação de ecossistemas. Além de serem ativamente deslocadas pelo homem, as gramíneas exóticas em geral competem com sucesso com as espécies nativas em uma grande variedade de ecossistemas. A invasão por gramíneas pode ser observada em todos os continentes, principalmente nas Américas. Na América do Sul, são espécies originárias da África, introduzidas pelo seu potencial forrageiro, que representam a maior ameaça à biodiversidade das savanas.

No Brasil, diversas gramíneas tropicais de origem africana foram introduzidas com essa finalidade e tornaram-se invasoras de reservas naturais, dispersando-se rápida e amplamente (Filgueiras 1991; Klink 1996). Por serem naturalmente abertos, os ecossistemas de campo cerrado e de campo sujo são os que mais sofrem a invasão por estas espécies, as quais apresentam alto grau de agressividade em relação às gramíneas nativas (Pivello et al. 1999a, b).

O sucesso das espécies africanas em deslocar as nativas na América do Sul pode ser atribuído a fatores ecofisiológicos, tais como a exploração mais eficiente dos recursos (Baruch \& Gomez 1996), a maior tolerância à desfoliação (Simões \& Baruch 1991), a capacidade de resistir melhor à seca sazonal (Baruch \& Fernandez 1993), taxas de germinação mais elevadas (Klink 1996), maior rapidez na recolonização de áreas queimadas e perturbadas (D'Antonio \&
Vitousek 1992) e similaridades na composição dos carboidratos solúveis de pronta utilização (Moraes et al. 2002).

Dentre as espécies com essas características podemos destacar Melinis minutiflora Beauv., que deslocou, por exemplo, espécies nativas como Trachypogum plumosus (Humb. \& Bonpl. ex Willd.) em savanas da Venezuela (Baruch \& Gomez 1996), agregando vantagens adaptativas como maior eficiência no uso de nitrogênio (Baruch et al. 1985), maior alocação de biomassa para produção de folhas, crescimento estolonífero e maior taxa de germinação (Baruch \& Gomez 1996). Melinis minutiflora também é uma das principais gramíneas invasoras de reservas naturais do Havaí, tendendo a ser a espécie dominante após as queimadas (D'Antonio et al. 2001). A introdução dessa espécie e de outras gramíneas exóticas nas florestas sazonais havaianas facilitou a ocorrência de fogo na estação seca levando a reduções no potencial de fixação de $\mathrm{N}$ das árvores nativas (Ley \& D'Antonio 1998).

No Brasil, Melinis minutiflora, onde é conhecida popularmente como capim-gordura, foi introduzida devido ao seu alto potencial forrageiro e se propagou rapidamente, tendo sido a principal espécie invasora observada em levantamentos realizados por Pivello et al. (1999a, 1999b) em unidades de conservação que visam a proteção do cerrado.

Entretanto, em um levantamento na Reserva Biológica do Cerrado de Emas, no município de Pirassununga, SP, Pivello et al. (1999a) observaram que a espécie nativa Echinolaena inflexa (Poir.) Chase apresentou padrões fitossociológicos e de distribuição espacial similares aos de M. minutiflora, sendo encontrados em ambas altos índices de biomassa aérea e de densidade. A associação positiva entre essas espécies indica que $M$. minutiflora não exclui a espécie nativa, embora possua metabolismo fotossintético $\mathrm{C}_{4}$, o que confere maior adaptação ao desenvolvimento em ambientes abertos, quentes e secos, como é o caso do cerrado.

Entre os fatores adaptativos que permitiriam a alta freqüência e a co-existência dessas espécies, destaca-se a grande capacidade de crescimento vegetativo, resultante da total conversão de fotoassimilados em biomassa alocada para as folhas (Klink 1996). A produção de biomassa, por sua vez, não é determinada apenas pela capacidade fotossintética, mas também pelo modo através do qual ocorre a partição dos fotoassimilados e a utilização dos mesmos durante o desenvolvimento da planta 
(Kingston-Smith et al. 1998). Nesse aspecto, o metabolismo de carboidratos tem papel preponderante.

\section{Perspectivas}

Apesar da importância ecológica e econômica dos carboidratos não-estruturais, relativamente pouco se conhece sobre a natureza e a regulação desses compostos em órgãos vegetativos de gramíneas (Smith et al. 2003). Assim, o conhecimento do metabolismo de tais carboidratos nas gramíneas do cerrado também faz-se necessário e poderá auxiliar na compreensão dos mecanismos ecofisiológicos desenvolvidos por essas plantas, como parte de uma possível estratégia de sobrevivência no cerrado. Esse conhecimento poderá ainda contribuir para avaliar a participação dos carboidratos no balanço de carbono do estrato herbáceo do cerrado e seu envolvimento na estabilidade desse bioma, face às invasões biológicas e de outras modalidades de perturbação ambiental.

\section{Referências bibliográficas}

Avigad, C. \& Dey, P. M. 1997. Carbohydrate metabolism: storage carbohydrates. Pp. 143-203. In: P.M. Dey \& J.B Harborne (eds.). Plant Biochemistry. London, Academic Press.

Bachmann, M.; Matile, P. \& Keller, F. 1994. Metabolism of the raffinose family oligosaccharides in leaves of Ajuga reptans $\mathrm{L}$. Cold acclimatation, translocation, and sink to source transition: Discovery of a chain elongation enzyme. Plant Physiology 105: 1335-1345.

Ball, S.G.; Van de Wal, M.H.B.J. \& Visser, R.G.F. 1998. Progress in understanding the biosynthesis of amylose. Trends in Plant Science - Reviews 3: 462-464.

Baruch, Z.; Ludlow, M.M. \& Davis, R. 1985. Photosynthetic responses of native and introduced $\mathrm{C}_{4}$ grasses from Venezuelan savannas. Oecologia 67: 288-393.

Baruch, Z. \& Fernandez, D.S. 1993. Water relations of native and introduced $\mathrm{C}_{4}$ grasses in a neotropical savanna. Oecologia 96: 179-185.

Baruch, Z. \& Gomez, J.A. 1996. Dynamics of energy and nutrient concentration and construction cost in a native and two alien $\mathrm{C}_{4}$ grasses from two neotropical savannas. Plant and Soil 181: 175-184.

Becking, J.H. 1981. The family Azobacteraceae. Pp. 795-817. In: M.P. Starr; H. Stolp \& H.G. Trüper (eds.). The prokariotes. New York, Springer-Verlag.

Bender, M.M. \& Smith, D. 1973. Classification of starchand fructosan- accumulating grasses as C-3 or C-4 species by carbon isotope analysis. Journal of the British Grassland Society 28: 97-100.

Bowyer, J.R. \& Leegood, R.C. 1997. Photosynthesis. Pp. 49-104. In: P.M. Dey \& J.B Harborne (eds.). Plant Biochemistry. London, Academic Press.
Buchi, R.; Bachman, M. \& Keller, F. 1998. Carbohydrate metabolism in source leaves of sweet basil (Ocimum basilicum L.), a starch-storing and stachyosetranslocating labiate. Journal of Plant Physiology 153: 308-315.

Carvalho, M.A.M. \& Dietrich, S.M.C. 1993. Variation in fructan content in the undergroung organs of Vernonia herbacea (Vell.) Rusby at different phenological phases. New Phytologist 123: 735-740.

Carvalho, M.A.M. \& Figueiredo-Ribeiro, R.C.L. 2001. Frutanos: ocorrência, estrutura e utilização, com ênfase em plantas do cerrado brasileiro. Pp. 77-89. In: Lajolo, F.M.; Saura-Calixto, F.; Penna, E.W. \& Menezes, E.W. (eds.). Fibra Dietética en Iberoamérica: Tecnología y Salud. São Paulo, Livraria Varela.

Castro, A.A.J.; Martins, F.R.; Tamashiro, J.Y. \& Shepherd, G.J. 1999. How rich is the flora of Brazilian cerrados? Annals of the Missouri Botanical Garden 86: 192-224.

Chapman, G.P. 1996. The biology of grasses. Wallingford, $\mathrm{CAB}$ International.

Chatterton, N.J.; Carlson G.E.; Hungerford, W.E. \& Lee, D.R. 1972. Effect of tillering and cool nights on photosynthesis and chloroplast starch in pangola. Crop Science 12: 206-208.

Chatterton, N.J.; Harrison, P.A.; Bennett, J.H. \& Asay, K.H. 1989. Carbohydrate partitioning in 185 accessions of Gramineae grown under warm and cool temperatures. Journal of Plant Physiology 134: 169-179.

Chatterton, N.J.; Thornley, W.R.; Harrison, P.A. \& Bennett, J.H. 1991. DP-3 and DP-4 oligosaccharides in temperate and tropical grass foliage grown under cool temperatures. Plant Physiology and Biochemistry 29: 367-372.

Crowe, J.H.; Hoekstra, F.A.; Nguyen, K.H. \& Crowe, L.M. 1996. Is vitrification involved in depression of the phase transition temperature in dry phospholipids? Biochimica et Biophysica Acta 1280: 187-196.

D'Antonio, C.M. \& Vitousek, P.M. 1992. Biological invasions by exotic grasses, the grass/fire cycle, and global change. Annual Review of Ecology and Systematics 23: 63-87.

D'Antonio, C.M.; Hughes, R. \& Vitousek, P.M. 2001. Factors influencing dynamics of two invasive grasses in seasonally dry Hawaiian woodlands. Ecology 82: 89-104.

Duchateau, N.; Bortlik, K.; Simmen, U.; Wiemken, A. \& Bancal, P. 1995. Sucrose:fructan 6-fructosyltransferase, a key enzyme for diverting carbon from sucrose to fructan in barley leaves. Plant Physiology 107: 1249-1355.

Edelman, J. \& Jefford, T.G. 1968. The mechanism of fructosan metabolism in higher plants as exemplified in Helianthus tuberosus L. New Phytologist 67: 517-531.

Farrar, J.; Pollock, C. \& Gallagher, J. 2000. Sucrose and the integration of metabolism in vascular plants. Plant Science 154: 1-11.

Filgueiras, T.S. 1991. A floristic analysis of the Gramineae of Brazil's Distrito Federal and a list of the species occurring in the area. Edinburgh Journal of Botany 48 : $73-80$. 
Filgueiras, T.S.; Fagg, J.M.F.; Silva Jr., M.C. \& Nogueira, P.E. 1998. Floristic and structural comparison of cerrado sensu stricto vegetation in Central Brasil. In: Forest Biodiversity in North, Central and South America, and the Caribbean. Research and Monitoring. New York, UNESO/MAB-The Parthenon Press.

Hibberd, J.M. \& Quick, P. 2002. Characteristics of $\mathrm{C}_{4}$ photosynthesis in stems and petioles of $\mathrm{C}_{3}$ flowering plants. Nature 415: 451-454.

Hoch, G.; Peterbauer, T. \& Richter, A. 1999. Purification and characterization of stachyose synthase from lentil (Lens culinaris) seeds: galactopinitol and stachyose synthesis. Archives of Biochemistry and Biophysics 266: 75-81.

Kandler, O. \& Hopf, H. 1984. Biosynthesis of oligosaccharides in vascular plants. Pp. 115-131. In: Storage Carbohydrates in Vascular Plants. Cambridge, Cambridge University Press.

Keller, F. \& Pharr, D.M. 1996. Metabolism of carbohydrates in sinks and sources. Galactosyl-Sucrose. Pp.157-184. In: Photoassimilate distribution in plants and crops: source-sink relationships. New York, Marcel Dekker, Inc.

Kellogg, E.A. 1998. Relationships of cereal crops and other grasses. Proceedings of the Natural Academy of Science 95: 2005-2010.

Kellogg, E.A. 2001. Evolutinary history of the grasses. Plant Physiology 125: 1198-1205.

Kingston-Smith, A.H.; Galthier N.; Pollock, C.J. \& Foyer, C.H. 1998. Soluble acid invertase activity in leaves is independent of species differences in leaf carbohydrates, diurnal sugar profiles and paths of phloem loading. New Phytologist 139: 283-292.

Klink, C.A. \& Joly, C.A. 1989. Identification and distribution of $\mathrm{C} 3$ and $\mathrm{C} 4$ grasses in open and shaded habitats in São Paulo State, Brazil. Biotropica 21: 30-34.

Klink, C.A. 1996. Competition between the African grass Andropogon gayanus Kunth and the native cerrado grass Schizachyrium tenerum Nees. Revista Brasileira Botânica 19: 11-15.

Koroleva, A.A.; Farrar, J.F.; Tomos, A.D. \& Pollock, C.J. 1998. Carbohydrates in individual cells of epidermis, mesophyll and bundle sheath in barley leaves with changed export or photosynthetic rate. Plant Physiology 118: $1525-1532$.

Larcher, W. 2000. Ecofisiologia vegetal. São Carlos, RiMa Artes e Textos.

Leopold, A.C.; Sun, W.Q. \& Bernal-Lugo, I. 1994. The glassy state in seeds: analysis and function. Seed Science Research 4: 267-274.

Ley, R.E. \& D'Antonio, C.M. 1998. Exotic grass invasion alters potential rates of $\mathrm{N}$ fixation in Hawaiian woodlands. Oecologia 113: 179-187.

Lewis, D.H. 1984. Storage carbohydrates in vascular plants: distribution, physiology and metabolism. London, Cambridge University.

Mantovani, W. \& Martins, F.R. 1988. Variações fenológicas das espécies do cerrado da Reserva Biológica de Moji-Guaçu, Estado de São Paulo. Revista Brasileira de Botânica 11: 101-112.

Medina, E.; Martinelli, L.A. \& Barbosa, E. 1999. Natural abundance of ${ }^{13} \mathrm{C}$ in tropical grasses from the INPA, Instituto Nacional de Pesquisas da Amazônia, herbarium. Revista Brasileira de Botânica 22: 44-51.
Moraes, M.G.; Souza, A.; Pessoni, R.A.B. \& FigueiredoRibeiro, R.C.L. 2002. Soluble carbohydrate similarities between Echinolaena infllexa and Melinis minutiflora (Poaceae). Hoehnea 29: 151-158.

Ong, M.H.; Jumel, K.; Tokarazuk, P.F.; Blanshard, J.M.V. \& Harding, S.E. 1994. Simultaneous determination of the molecular-weight distributions of amyloses and the fine structures of amylopectins of native starches. Carbohydrate Research 260: 99-117.

Peterbauer, T.; Puschenreiter, M. \& Richter, A. 1998. Metabolism of galactosylononitol in seeds of Vigna umbellata. Plant and Cell Physiology 39: 334-341.

Peterbauer, T. \& Richter, A. 2001. Biochemistry and physiology of raffinose family oligosaccharides and galactosyl cyclitols in seeds. Seed Science Research 11: $185-197$.

Pivello, V.R.; Carvalho, V.M.C.; Lopes, P.F.; Peccinini, A.A. $\&$ Rosso, S. 1999a. Abundance and distribution of native and alien grasses in a "cerrado" (Brazilian savanna) biological reserve. Biotropica 31: 71-82.

Pivello, V.R.; Shida, C.N. \& Meirelles, S.T. 1999b. Alien grasses in Brazilian savannas: a threat to the biodiversity. Biodiversity \& Conservation 8: 1281-1294.

Pollock, C.J. 1984 Sucrose accumulation and initiation of fructan biosynthesis in Lolium temulentum L. New Phytologist 96: 527-534.

Pollock, C.J. 1986. Environmental effects on sucrose and fructan metabolism. Current Topics of Plant Biochemistry and Physiology 5: 32-42.

Pollock, C.J.; Winters, A.L.; Gallagher, J. \& Cairns, A.J. 1995. Sucrose and the regulation of fructan metabolism in leaves of temperate gramineae. Sucrose Metabolism, Biochemistry, Physiology and Molecular Biology 14: 167-178.

Pollock, C.J. \& Cairns, A.J. 1991. Fructan metabolism in grasses and cereals. Annual Review of Plant Physiology and Molecular Biology 42: 77-101.

Raven, P.H.; Evert, R.F. \& Eichhorn, S.E. 1999. $6^{\text {th }}$ ed. Biology of Plants. New York, W.H. Freeman and Company.

Richter, A.; Hoch, G.; Ouschenreiter, M.; Mayer, U. \& Peterbauer, T. 2000. The role of stachyose synthase in the oligosaccharide metabolism of legume seeds. In: Seed Biology. Advances and Applications. Wallingford, UK, CAB International.

Rodrigues-da-Silva, R. \& Filgueiras, T. 2003. Gramíneas (Poaceae) da Área de Relevante Interesse Ecológico (ARIE) Santuário de Vida Silvestre do Riacho Fundo, Distrito Federal, Brasil. Acta Botanica Brasilica 17(3): 467-486.

Sage, R.F. 2004. The evolution of $\mathrm{C}_{4}$ photosynthesis. New Phytologist 161: 341-370.

Simões, M. \& Baruch, Z. 1991. Responses to simulated herbivory and water stress in two tropical $\mathrm{C}_{4}$ grasses. Oecologica 88: 173-180.

Smith, A.M.; Zeeman, S.C.; Thorneycroft, D. \& Smith, S.M. 2001. Starch mobilization in leaves. Journal of Experimental Botany 54: 577-583. 
Steenhoudt, O. \& Vanderleyden, J. 2000. Azospirillum, a free-living nitrogen-fixing bacterium closely associated with grasses: genetic, biochemical and ecological aspects. FEMS Microbiological Review 24: 487-506.

Vitousek, P.M. 1990. Biological invasions and ecosystem processes: towards an integration of population biology and ecosystem studies. Oikos 57: 7-13.
Voznesenskaya, E.V.; Franceschi, V.R.; Kiirats, O.; Freitag, H. \& Edwards, G.E. 2001. Kranz anatomy is not essential for terrestrial $\mathrm{C}_{4}$ photosynthesis. Nature 414: 543-546. Zeeman, S.C.; Tiessen, A.; Pilling, E.; Kato, K.L.; Donald, A.M. \& Smith, A.M. 2002. Starch synthesis in Arabidopsis. Granule synthesis, composition and structure. Plant Physiology 129: 516-529. 